\title{
ANÁLISE MICROESTRUTURAL DO AÇO 1018 APÓS ENSAIO DE CORROSÃO
}

\author{
Arthur de Sousa Gomes Nogueira, Ygor Peixoto Rangel ${ }^{1}$, Thais dos Santos Oliveira ${ }^{1}$ e \\ Geanni Barbosa da Silveira e Silva ${ }^{2 *}$
}

\begin{abstract}
RESUMO
GOMES, A.S.; RANGEL, Y.P.; OLIVEIRA, T.S.; SILVA, G.B.S. Análise Microestrutural do Aço 1018 após ensaio de corrosão. Perspectivas Online: Exatas \& Engenharias, v. 7, n.18, p.01-08, 2017.

É indiscutível a aplicabilidade dos materiais metálicos na indústria. O bom emprego de determinados materiais dependem diretamente do meio onde serão utilizados, das propriedades necessárias, custo-benefício, entre outros fatores. Dentre os aços mais comumente utilizados, destaca-se o aço 1018. Os aços de baixo teor de carbono são relativamente fáceis de serem usinados em qualquer modelo de máquina, além de poderem ser conformados facilmente. Porém, os mesmos não apresentam resistência à corrosão, que é um fator imprescindível para que as propriedades e vida útil sejam mantidas. A cada dia as empresas visam minimizar os custos que envolvem a corrosão, sendo assim,

necessitam cada vez mais aprimorar os conhecimentos sobre esse assunto tão relevante. Para que isso ocorra há uma crescente perspectiva no desenvolvimento de técnicas, análises, assim como métodos preventivos. Através desse trabalho foi possível acompanhar o comportamento do aço 1018 após ensaio de corrosão e identificada morfologia obtida. Esperava-se um acometimento localizado maior, porém a corrosão generalizada foi a predominante, sendo classificada como severa, segundo a norma NACE Standard RP0775 (2005). Esses resultados foram alcançados através de análises, ensaios e caracterizações através de normas.
\end{abstract}

Palavras-chave: Aço carbono; Corrosão; Ensaios; Caracterização. 


\begin{abstract}
The applicability of metallic materials in industry is indisputable. The good use of certain materials depends directly on the environment where they will be used, the necessary properties, cost-benefit, among other factors. Among the most commonly used steels, 1018 steel stands out. Low-carbon steels are relatively easy to machine in any machine model, and can be easily shaped. However, they do not present resistance to corrosion, which is an essential factor for the properties and useful life to be maintained. Every day companies aim to minimize the costs involved

improve their knowledge on this important subject. For this to occur there is a growing perspective on the development of techniques, analyzes, and preventive methods. Through this work it was possible to follow the behavior of 1018 steel after corrosion test and to identify the obtained morphology. A greater localized involvement was expected, but generalized corrosion was the predominant one, being classified as severe according to NACE Standard RP0775 (2005). These results were achieved through analysis, testing and characterization through standards.
\end{abstract} in corrosion, and therefore, they need to

Keywords: Carbon steel; Corrosion; Testing; Characterization.

\footnotetext{
${ }^{1}$ Institutos Superiores de Ensino do CENSA - ISECENSA - Acadêmico do Curso de Graduação em Engenharia Mecânica - Rua Salvador Correa, 139, Centro, Campos dos Goytacazes, RJ, CEP: 28035-310, Brasil;

${ }^{2 *}$ Institutos Superiores de Ensino do CENSA - ISECENSA - Laboratório de Metrologia - Rua Salvador Correa, 139, Centro, Campos dos Goytacazes, RJ, CEP: 28035-310, Brasil;
}

(*)e-mail: gi_silveira@hotmail.com

Data de chegada: 20/05/2017 Aceito para publicação: 28/07/2017 


\section{INTRODUÇÃO}

As ligas de aço com baixo teor de carbono apresentam muitas aplicações. Uma das mais populares variedades de liga é o aço 1018, que é relativamente fácil de ser usinado em qualquer modelo de máquina, além de poder ser moldado e soldado facilmente. Designadamente o setor petrolífero prefere a utilização do aço carbono de baixa liga, os quais estão mais facilmente disponíveis e satisfazem os requerimentos mecânicos, estruturais, de propriedades e custos de fabricação. Entretanto são pouco resistentes à corrosão. [7]

A corrosão afeta os mais diversos setores onde são empregados, prejudicam a durabilidade e desempenho de estruturas, máquinas, equipamentos e ferramentas. Seu estudo é imprescindível para evitar impactos econômicos desnecessários com manutenção indesejada e de segurança. Como forma de minimizar estes prejuízos, as empresas tem se preocupado em acompanhar tais processos corrosivos.[3]

Como técnica de avaliação de processos corrosivos, os cupons de perda de massa vem se destacando, de forma que os corpos de prova são imersos em meio específico em laboratório e a partir do que for gerado realiza-se o estudo adequado. [5]

A avaliação da corrosão é uma forma qualitativa de analisar o processo corrosivo e ter uma noção da extensão do ataque no corpo de prova. A observação visual é a mais simples, que permite determinar se o ataque é uniforme ou localizado. Após a observação visual detalhada, executa-se a limpeza da peça. Essa limpeza pode ser mecânica, química ou eletrolítica, tomando cuidado para não atacar a parte do metal não afetada. Para uma análise mais minuciosa da morfologia, pode-se utilizar a microscopia óptica. [3]

Analisando os tipos de corrosão e conhecendo seus mecanismos e causas, torna-se possível adotar métodos de prevenção e minimizar a ocorrência desses fenômenos. Dos quais podemos destacar, a seleção de materiais mais resistentes, alteração da natureza do ambiente, revestimentos o material contra uma deterioração apreciável. [2]

Este trabalho tem o objetivo de investigar os efeitos da corrosão no aço 1018, onde foram avaliadas as formas de corrosão geradas em meio aquoso doce.

\section{METODOLOGIA}

Foram utilizados 2 cupons para o experimento, onde um foi imerso em meio aquoso natural em um período de 6 meses e o outro foi utilizado como base comparativa após o ensaio. A partir deste comparativo pode-se perceber o quanto a corrosão afetou a microestrutura do material e constatar a relação da corrosão com a perda de propriedades.

Cada cupom foi imerso em embalagens do tipo PET com volume aproximado de 2 litros. Após o ensaio, foi realizada a decapagem química dos cupons para a retirada do produto de corrosão depositado, para tal procedimento foi utilizada a norma ABNT NBR 6210 [1] como referência. E por fim, o ensaio micrográfico para a detecção da forma de corrosão apresentada. 


\section{- Material Utilizado}

O material analisado foi um aço 1018, que é comumente usado na fabricação de tubos na indústria offshore, que tem sua composição química e propriedades mecânicas mais detalhadas no quadro abaixo (Quadro I).

Quadro I: Composição química e propriedades mecânicas do material utilizado

\begin{tabular}{|c|c|c|c|}
\hline Elementos & $\mathbf{\%}$ & Propriedades & Valor \\
\hline $\mathrm{C}$ & 0,1570 & $\mathrm{HB}$ & 116 \\
\hline $\mathrm{Si}$ & 0,1710 & $\mathrm{~A}\left(2^{\prime \prime}\right) \%$ & 25 \\
\hline $\mathrm{Mn}$ & 0,7510 & LR (Mpa) & 400 \\
\hline $\mathrm{P}$ & 0,0181 & LE (Mpa) & 220 \\
\hline $\mathrm{S}$ & 0,0082 & $\mathrm{Z}(\%)$ & 50 \\
\hline $\mathrm{Nb}$ & $<0,001$ & - & - \\
\hline $\mathrm{Cr}$ & 0,0223 & - & - \\
\hline $\mathrm{Ti}$ & 0,0010 & - & - \\
\hline $\mathrm{Mo}$ & 0,0104 & - & - \\
\hline $\mathrm{V}$ & 0,0038 & - & - \\
\hline $\mathrm{Cu}$ & 0,0917 & - & - \\
\hline $\mathrm{Fe}$ & 98,600 & - & - \\
\hline $\mathrm{Impurezas}$ & - & - & - \\
\hline
\end{tabular}

Fonte: Laboratório de Materiais Avançados (LAMAV) - UENF.

O cupom pode ser observado abaixo (Figura 1) juntamente com as dimensões.

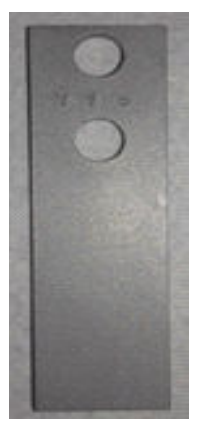

Espessura: 3,20mm

Largura: $22,15 \mathrm{~mm}$

Comprimento: $73,16 \mathrm{~mm}$

Figura 1: Cupom e suas dimensões.

\section{-Meio Utilizado}

A água foi retirada do rio Paraíba do Sul (Latitude: -21.62678; Longitude: -41.386456) e colocada em uma garrafa do tipo PET onde o cupom foi imerso (Figura 2). 


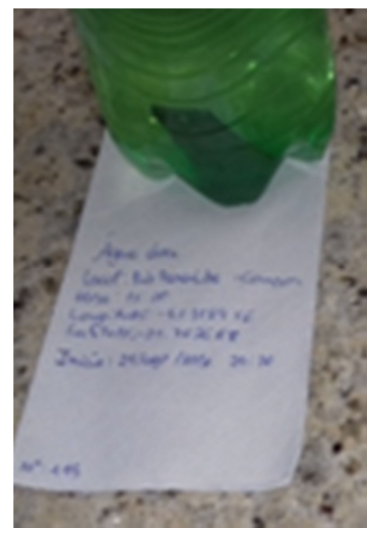

Figura 2: Cupom imerso em meio aquoso natural.

\section{- Ensaio de Corrosão}

Segundo o andamento do ensaio, verificou-se que com 1 mês de permanência seria suficiente para a formação de produto de corrosão, porém para maior efetividade do ensaio o cupom permaneceu exposto por três meses (Figura 3). Durante o ensaio, foram coletadas medidas semanais de pH, com o objetivo de manter estabilidade neste parâmetro durante o período do ensaio. Realizado o ensaio, o objetivo foi alcançado, o cupom foi acometido pela corrosão em toda sua extensão.

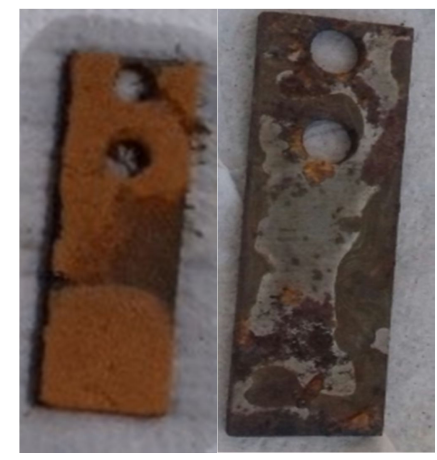

Figura 3: Cupom após o ensaio.

\section{- Decapagem Química}

Assim que o cupom foi retirado do meio, foi realizada a decapagem. Esse procedimento foi realizado com base na norma 6210 NBR [1], onde o cupom foi imerso por 10 minutos em Solução de Clarke (Figura 4). Após esse processo as amostras foram lavadas com água corrente fraca para retirada dos resíduos do ácido e secas. 


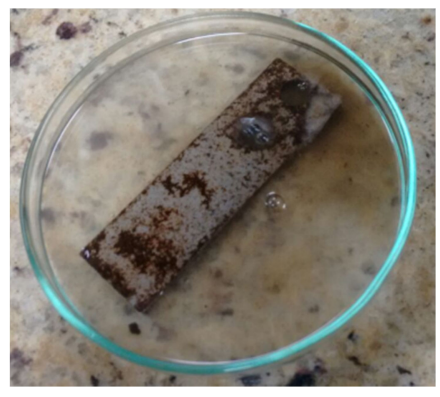

Figura 4: Cupom em decapagem química.

\section{- Ensaio Micrográfico}

Foi utilizado o microscópio ótico Olympus Gx 41 (Figura 5) para analisar a morfologia obtida no ensaio de corrosão.

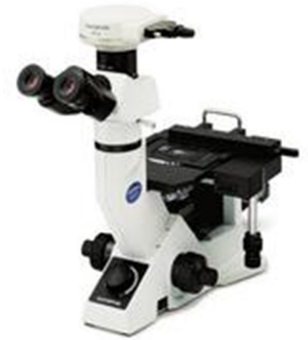

Figura 5: Microscópio ótico Olympus Gx 41.

\section{CONSIDERAÇÕES FINAIS}

Assim que o cupom foi decapado, o primeiro resultado adquirido foi a perda de massa através da pesagem do mesmo. No quadro II serão expostos os pesos registrados (inicial e final) para verificação de perda de massa, caracterizada pela corrosão uniforme.

Quadro II: Pesagem das amostras

\begin{tabular}{|c|c|c|}
\hline Peso inicial & Peso após decapagem & Perda de massa (\%) \\
\hline $38,186 \mathrm{~g}$ & $37,400 \mathrm{~g}$ & 2,058346 \\
\hline
\end{tabular}

Segundo a norma NACE Standard RP0775-2005 [4], o cálculo da taxa média de corrosão (CR), expresso como uma taxa uniforme de perda de massa pela espessura é expressa em milímetros por ano $(\mathrm{mm} / \mathrm{a})$, é mostrado na equação (1):

$$
C R=\frac{W \times 365 \times 1,000}{A T D}=\frac{3.65 \times 10^{5} \times W}{A T D}
$$


*CR: taxa média de corrosão uniforme; ${ }^{*} \mathrm{~W}$ : perda de massa; ${ }^{*} \mathrm{~A}$ : área inicial exposta; *T: tempo de exposição; *D: densidade do metal.

Através da equação foi obtida uma taxa média de corrosão uniforme de $0,3178 \mathrm{~mm} / \mathrm{a}$, de forma que a perda de massa é convertida em perda de espessura total, ou taxa de corrosão generalizada. Através do valor, o processo corrosivo foi classificado como designa a NACE RP0775 [4] apresentada na tabela 1.

Tabela I: Classificação qualitativa dos aços-carbono quanto à taxa de corrosão uniforme

$$
\text { Taxa de Corrosão Uniforme (mm/ano) }
$$

\begin{tabular}{cc}
\hline Baixo & $<0,025$ \\
\hline Moderado & $0,025-0,12$ \\
\hline Alto & $0,13-0,25$ \\
\hline Severo & $>0,25$ \\
\hline
\end{tabular}

Fonte: NACE, 2005.

Pode-se concluir, portanto, que a corrosão uniforme neste ensaio foi considerada severa. Ainda com o propósito de analisar a morfologia da corrosão localizada, foi realizada uma análise micrográfica do cupom, de modo que foi detectada algumas escavações (Figura 6), que confrontando com a bibliografia, pode-se identificá-la como corrosão por placas. Segundo [3] a corrosão por placas se localiza em regiões da superfície e não em toda sua extensão, formando placas com escavações.

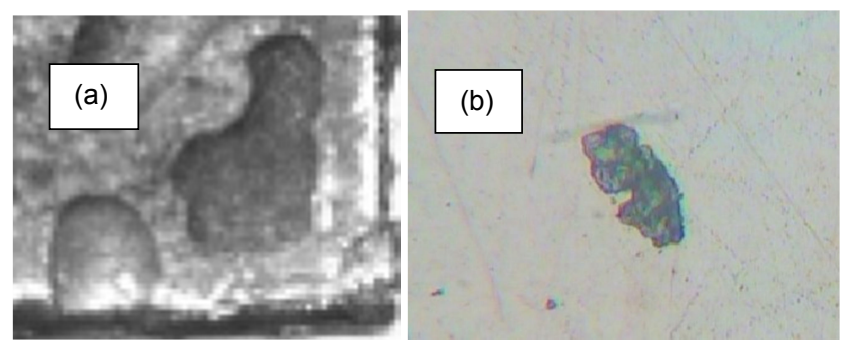

Figura 6: Comparação entre a corrosão por placas (a) e a corrosão detectada (b).

De forma esperada o aço 1018 obteve baixa resistência à corrosão, contudo houve um maior ataque generalizado do que localizado, o que pode-se destacar a relevante e necessária proteção anticorrosiva que irá atuar como uma película protetora deficiente nesse tipo de material. 


\section{REFERÊNCIAS BIBLIOGRÁFICAS}

[1] ABNT 6210 NBR. Corrosão atmosférica - Materiais metálicos - Preparo, limpeza e determinação da taxa de corrosão de corpos-de-prova em ensaios de corrosão, ISBN 978-85-07-01103-3, 9p., 2008.

[2] CALLISTER JR., W.D. Ciência e Engenharia de Materiais: Uma Introdução, $5^{\text {a }}$ Edição. Editora LTC, 2000.

[3] GENTIL, V., Corrosão. 6 edição, Rio de Janeiro: LTC, 2012.

[4] Nace Standard RP0775 (2005). Preparation, Instalation, Analysis, and Interpretation of Corrosion Coupons in Oilfield Operations, item n ${ }^{\circ}$ 21017, ISBN 1-57590-086-6, 2005.

[5] SILVA, G. B. S. Caracterização de Cupons de Corrosão através de Diferentes Técnicas Comparativas. UENF, 2014.

[6] SILVEIRA, G. B. et al. Microscopia Óptica e Microscopia Confocal como Técnicas Comparativas para Caracterização de Pites em Cupons de Corrosão.INTERCORR, 2014, Fortaleza, CE.

[7] VIDOR, G. F.; LOPES, N. F.; MARCOLINO, J. B.; MORAES, M. K.; COSTA, E. M. Influência da microestrutura do aço ao carbono SAE 1045 na corrosão por $\mathrm{CO} 2$ a alta pressão e a alta temperatura nos estados: encruado, recozido e temperado e revenido.CBECIMAT, 2014, Cuiabá, MT. 